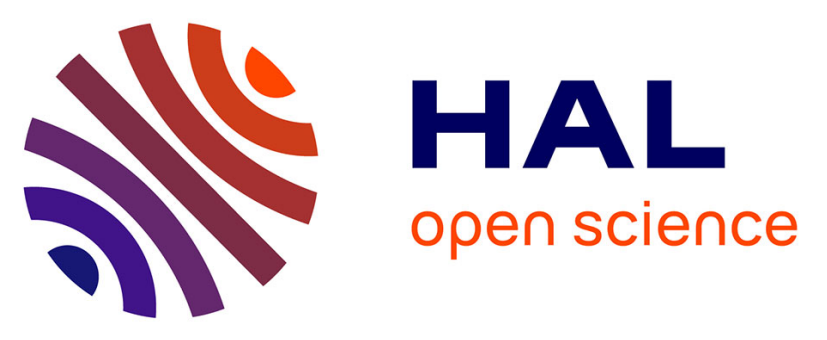

\title{
Spirulina platensis Provides a Small Advantage in Vertical Jump and Sprint Performance But Does Not Improve Elite Rugby Players' Body Composition
}

Mehdi Chaouachi, Sandrine Gautier, Yoann Carnot, Nicolas Bideau, Pierrick Guillemot, Yann Moison, Tom Collin, S Vincent, Carole Groussard

\section{- To cite this version:}

Mehdi Chaouachi, Sandrine Gautier, Yoann Carnot, Nicolas Bideau, Pierrick Guillemot, et al.. Spirulina platensis Provides a Small Advantage in Vertical Jump and Sprint Performance But Does Not Improve Elite Rugby Players' Body Composition. Journal of Dietary Supplements, 2021, 18 (6), pp.682-697. 10.1080/19390211.2020.1832639 . hal-03001268

\section{HAL Id: hal-03001268 \\ https://hal.science/hal-03001268}

Submitted on 21 Jan 2021

HAL is a multi-disciplinary open access archive for the deposit and dissemination of scientific research documents, whether they are published or not. The documents may come from teaching and research institutions in France or abroad, or from public or private research centers.
L'archive ouverte pluridisciplinaire HAL, est destinée au dépôt et à la diffusion de documents scientifiques de niveau recherche, publiés ou non, émanant des établissements d'enseignement et de recherche français ou étrangers, des laboratoires publics ou privés. 
2 Spirulina platensis provides a small advantage in vertical jump and sprint

3 performance but does not improve elite rugby players' body composition

\section{RUNNING TITLE: Spirulina as an ergogenic nutrient in athletes?}

6 Authors: Chaouachi Mehdi ${ }^{a^{*}}$, Gautier Sandrine ${ }^{\mathrm{a}}$, Carnot Yoann ${ }^{\mathrm{b}}$, Bideau Nicolas ${ }^{\text {a }}$, Guillemot

7 Pierrick $^{\mathrm{ac}}$, Moison Yann ${ }^{\mathrm{ab}}$, Collin Tom ${ }^{\mathrm{a}}$, Vincent Sophie ${ }^{\mathrm{a} \#}$ \& Groussard Carole ${ }^{\mathrm{a} \#}$

8

$9{ }^{a}$ Univ-Rennes, Laboratoire M2S - UR7470, F-35000 Rennes, France.

10 b REC Rugby, 35000 Rennes, France.

$11{ }^{\mathrm{c}}$ Univ-Rennes, CHU Rennes 1, service de médecine du sport, F-35000 Rennes, France.

$12{ }^{\#}$ both authors contributed equally to the work.

* Corresponding author: Chaouachi Mehdi

15 Univ-Rennes, Laboratoire M2S - UR7470, F-35000 Rennes, France,

14 Avenue Robert Schuman, 35170 Bruz, France.

17 Email: chaouachimehdi@hotmail.com

Tel number: +33785155469

CONFLICT OF INTEREST: The authors declare no conflict of interest with the

21 information contained within this manuscript. 


\section{ABSTRACT}

The present study aimed to examine the effects of Spirulina supplementation on anthropometrical measurements and physical performance in elite rugby players.

Twenty-two elite male Rugby Union players (21-36 years old) volunteered to participate in this study. They were randomly assigned to a Spirulina group (SPI: $n=11$ ), or a placebo group (PLA: $\mathrm{n}=11)$ in a double-blind design. Subjects were supplemented with Spirulina platensis $(5.7 \mathrm{~g} / \mathrm{d})$ or Placebo (iso-proteic and caloric) for seven weeks. At baseline $\left(\mathrm{W}_{0}\right)$ and after 7 weeks of supplementation $\left(\mathrm{W}_{7}\right)$, the same anthropometric measurements and physical performance test battery were performed. These tests included isokinetic leg strength and power, vertical jump, speed, and aerobic fitness assessment.

For anthropometric data, the fat mass (FM) percentage was significantly reduced in both groups without significant difference between groups. While both groups exhibited significant improvements for SJ, CMJ, 10 and 30-m sprints between W0 and $\mathrm{W} 7$, higher percentage improvements with the SPI group did not reach significance. Neither training alone (PLA) nor training associated with spirulina supplementation affected leg maximal strength and power or aerobic fitness.

Seven weeks of spirulina supplementation in elite rugby players did not improve body composition nor substantially increase physical performance. We only observed a nonsignificant small advantage in vertical jump and sprint performance in the SPI group. Based on the data from this study, spirulina supplementation has modest effects in elite rugby players during the competitive phase. Further studies are required to verify spirulina supplementation effects among athletes of different sports, age, gender and athletic level with longer durations and higher dosages.

KEY WORDS: Arthrospira, body composition, elite athletes, performance, supplementation. 


\section{Introduction}

Spirulina (Arthrospira) is a blue-green microalga belonging to the Cyanobacteria class with prokaryotic photosynthetic characteristics [1-4]. The most well-known species of spirulina safe for consumption are Spirulina maxima, Arthrospira fusiformis, and platensis, this last one being the most commonly used species and largely studied in the scientific literature $[4,5]$. It's known for its complex chemical makeup including high protein content (50 to $70 \%$ of its dry weight), all the essential amino and fatty- acids, and most of the vitamins and minerals [6-8], which confers to spirulina numerous health benefits such as antioxidant, immunomodulatory, antiinflammatory, anti-cancer and anti-viral activities [1, 8-10].

In recent years, spirulina has been widely used by athletes for these health benefit effects and most of them consume it in the belief it will improve body composition, physical performance and recovery. It was speculated that Chinese and Cuban Olympic teams have consumed spirulina daily for many years to improve performance [2]. Data in the literature is still rare and controversial about spirulina effects on anthropometric parameters and performances in athletes. Indeed, only a few authors investigated the effects of spirulina supplementation on these data in athletes. Concerning anthropometric parameters, in untrained subjects, Miczke et al. [11] and Zeinalian et al. [12] indicated a loss of body mass (BM: -6\%) without changes in fat mass (FM). However, Lee et al. [13] and Mazokopakis et al. [14] reported no significant effects on these parameters. In athletes, Milasius et al. [15] reported no significant decrease in $\mathrm{BM}$ and FM after supplementation $(2.25 \mathrm{~g} / \mathrm{d})$ which may suggest no change in lean body mass (LBM) or muscle mass contrary to spirulina assertions. Concerning spirulina effects on performance, Lu et al. [16] studied the effects of three weeks of Arthrospira platensis supplementation $(7.5 \mathrm{~g} / \mathrm{d})$ in students and reported a significantly increased time to exhaustion during the Bruce protocol test only in the spirulina group. In moderately trained men, Kalafati et al. [17] showed that time to fatigue after a submaximal run was significantly higher after 
spirulina supplementation $(6 \mathrm{~g} / \mathrm{d})$. Concerning the effects of spirulina consumption on muscular strength, Sandhu et al. [18] examined the effects of eight weeks of spirulina supplementation $(2 \mathrm{~g} / \mathrm{d})$ in trained and untrained subjects. They reported significant improvements in isometric peak force, average force, and fatigue index due to the use of spirulina for both groups. Therefore, they recommend the use of spirulina as a nutritional supplement by athletes and nonathletes for improving isometric strength and muscle endurance. Recently and contrary to these conclusions, Juszkiewicz et al. [19] showed that spirulina supplementation $(1.5 \mathrm{~g} / \mathrm{d})$ was not able to enhance the mean power output nor total run time during a $2000-\mathrm{m}$ test on a rowing ergometer with a Polish rowing team. Among the four studies which evaluated the effects of spirulina on physical performance, only one examined elite athletes [19] and they only tested the effect of spirulina on muscle power and not on various physical qualities. In addition to the low level of evidence and the heterogeneity of previous studies concerning the types of the sport involved, the duration and dose of supplementation, to our knowledge, no studies have examined the effects of spirulina supplementation in team-sport athletes although they are known for their widespread use of ergogenic aids [20, 21].

Thus, the aim of the present study was to examine the effects of spirulina supplementation on anthropometric measurements and physical performance in elite rugby players. Physical performance evaluation included a complete set of measurements such as leg strength and power, vertical jump, speed, and aerobic fitness. We hypothesized that its high nutritional quality protein content could reduce FM and possibly increase lean body mass (LBM), leading to a greater improvement in performance.

\section{Materials and methods}

The experimental protocol was approved by a local ethics committee (NOD0172, Tours, France - protocol number 2016-A00233-48). The protocol was conducted in compliance with both Good Clinical Practices and the Declaration of Helsinki. Tests were realized at M2S lab (FINES 
of 31/05/17; EJ: 350051454; ET: 350051462). After being informed of the objectives, the possible risks, discomforts and benefits, written and informed consent was obtained from all participants prior to inclusion.

\section{Participants}

Thirty elite male rugby union players belonging to the same French first federal division rugby club (Rennes Étudiants Club « REC ») volunteered to participate in this study. After having completed a clinical examination and medical interview to determine eligibility, only twentytwo participants (21-36 years old) satisfied the following inclusion criteria (being considered healthy in clinical examination, not having any history of surgery and not taking any kind of dietary supplement for the past 3 months). Exclusion criteria included tobacco use, current intake of spirulina, supplements or anti-inflammatory drugs, known chronic diseases and allergy to spirulina or any of its components.

\section{Study design}

A randomized, double-blind, placebo-controlled design was used. Sealed opaque envelopes numbered in the order of inclusions, with the allocated treatment listed in the envelope, were constructed from the established randomization list. The draw was conducted by a third party who held the codes assigned to the subjects and used for data collection. Participants were assigned to a spirulina group (SPI: $n=11$ ), or a placebo group PLA: $n=11$ ). Participant characteristics are reported in Table $\mathbf{1 .}$

$<<$ Please insert table 1 here $>>$ 
123 The study consisted of a daily supplementation period during 7 weeks in which the SPI group 124 received capsules with Arthrospira platensis, manufactured by Algae Green Value (AGV, 125 Vannes, France). This spirulina is certified as safe and its composition is reported in Table 2. 126 $<<$ Please insert table 2 here $>>$

Each subject was asked to take three capsules before the three daily meals. Based on the doses used in the previous human studies and taking into account the comfort of participants, the daily dosage was $5.7 \mathrm{~g}$, below the $10 \mathrm{~g}$ safety dosage recommended by Fox [22]. The placebo group 132 was given visually identical capsules with isocaloric and isoproteic content composed of 70.3 $133 \%$ egg proteins and $29.7 \%$ carbohydrates.

Rugby players visited the laboratory five times during the study. The same anthropometric measurements and physical performance test battery were performed at baseline (W0) and after seven weeks of supplementation (W7). These tests included leg strength and power, vertical 137 jump, speed, and aerobic intermittent fitness test (yo-yo IRT-1). At W0 and W7, all subjects 138 were asked to record dietary intake for three days including one weekend day. Diet records were analyzed using the Nutrilog software (Nutrilog ${ }^{\circledR}$ SAS, France). Players were invited to make 140 no modifications to their diet and to not use any other dietary supplements during the study or 141 risk being excluded.

142 Supplementation compliance was assessed by counting the remaining capsules in the provided 143 bottles at the end of the study. Gastrointestinal symptoms were monitored using a questionnaire 144 as described by Bovenschen et al. [23]. The study design is illustrated in Figure 1. 


\section{Procedures}

All procedures were conducted during the competitive phase of the season (October-December 2018). All participants actively participated daily in the rugby-specific training sessions. They were fully accustomed to the testing procedures used in this research as they routinely performed these tests in the club as part of their medical/training follow-up.

\section{Anthropometric data and body composition}

Each participant's height, BM and FM were collected. Height and BM were collected using a wall-mounted stadiometer (Seca 206, Hamburg, Germany) and electronic scale (Terraillon, Paris, France), respectively. FM percentage was estimated from the sum of skinfolds (biceps brachii, triceps brachii, subscapular, and supra-iliac) monitored with Harpenden skinfold calipers (Baty International, West Sussex, England) according to Siri [24]. All anthropometric measurements were taken at W0 and W7 by the same experienced sports scientist.

\section{Training load}

Throughout the experiment, the internal training load of all players was monitored using the session Rate of Perceived Exertion (Session-RPE) method as described by Comyns and Flanagan [25] expressed in arbitrary units (AU). About 30-minutes (min) after training sessions, participants were asked to rate the global intensity of the entire workout session using the French version CR-10 RPE scale [26]. The daily training load was evaluated by multiplying the training duration (min) by the session RPE score and the weekly training load was determined by summing the daily training loads each week for each rugby player.

\section{Physical fitness tests}


172 Prior to each testing session, participants completed a 15-min standardized warm-up that

173 included riding a cycle ergometer (Excalibur, Lode, Groningen, Netherlands) and dynamic

174 stretching. All testing sessions were completed at the same moment of the day for both W0

175 and W7, at the same turf pitch, with the same sports clothes, in the same order (Fig. 1) and by

176 the same investigators.

177

$178 \quad$ Isokinetic leg strength and power

179 Subjects were comfortably seated on the dynamometer chair, with the hip joint at a standardized 180 position of $85^{\circ}$ hip flexion from the anatomical position. Straps were applied across the chest, 181 pelvis, and mid-thigh to minimize extraneous body movements. The distal shin pad of the 182 dynamometer was attached $2-3 \mathrm{~cm}$ proximal to the lateral malleolus by using a strap. The axis 183 of rotation of the dynamometer was aligned with the lateral femoral epicondyle of the knee. 184 Gravity torque effects were recorded on each subject throughout the range of motion to correct 185 torque measurements during testing. The participants were given standardized verbal 186 encouragement and were asked to position their arms across the chest with each hand clasping 187 the opposite shoulder during the testing procedure. The thigh muscles of the dominant limb 188 were tested by using an isokinetic dynamometer (CON-TREX ${ }^{\circledR}$ MJ; CMV AG, Dübendorf, 189 Switzerland) as described by Maffiuletti et al. [27]. Subjects were asked to complete three 190 submaximal practice repetitions prior to each test series. Concentric measurements involved 191 three continuous, maximal knee extensions and flexions, which were performed at two pre-set 192 constant angular velocities, 60 and $240{ }^{\circ} \mathrm{s}^{-1}$. Eccentric measurements consisted of three maximal 193 contractions at a single velocity of $30^{\circ} \mathrm{s}^{-1}$. Knee flexor and extensor trials were performed as 194 movements in a single direction (i.e. non-reciprocal). Subjects recovered passively for 120s 195 between series of measurements. The Con-Trex software calculated the peak torque and power 196 for concentric and eccentric trials in knee extensors and flexors. 
197

198

199

200

201

202

203

204

205

206

207

208

209

210

211

212

213

214

215

216

217

218

219

220

\section{Vertical jump}

Players performed the vertical jumps: squat jump (SJ) and countermovement jump (CMJ), using an Optojump next photocell system (Microgate, Bolzano, Italy), which are valid and reliable tools for the assessment of vertical jump height [28, 29]. Participants were instructed to place their hands on the hips to minimize lateral and horizontal displacement during the performance and to prevent any influence of arm movements on the vertical jumps. Participants also had to leave the ground with the knees and ankles extended and land in the same position and location to minimize horizontal displacement and influence on flight time. For SJ, the participant started from a stationary semi-squat position (knee angle $\sim 90^{\circ}$ ), held a three-second count and jumped vertically as high as possible. For CMJ, the participant started from an upright standing position, performed a very fast preliminary downward movement, flexing and then extended his knees and hip to jump vertically as high as possible off the ground. Three trials per test were performed with approximately 2 -min recovery and the best result was used for analysis.

\section{Speed}

Running speed was evaluated using a stationary $10-\mathrm{m}$ and $30-\mathrm{m}$ sprint test as described by Chaouachi et al. [30]. Players were located $20-\mathrm{cm}$ behind the start line position and were instructed to run as quickly as possible along the $30-\mathrm{m}$ distance. Time was automatically recorded using photocell gates (Witty system, Microgate, Italy, accuracy of $0.01 \mathrm{~s}$ ) placed 0.4-m above the ground. Participants performed two trials with at least 2-min rest between trials. The run with the lowest $30-\mathrm{m}$ time was selected for analysis.

Aerobic fitness 
221 Players performed the Yoyo Intermittent Recovery Test Level 1 (Yoyo IRT-1) as described by 222 Krustrup et al. [31]. This test focuses on the capacity to carry out intermittent exercise leading 223 to maximal activation of the aerobic system [32]. It consists of $2 \times 20-\mathrm{m}$ runs back and forth 224 between starting, turning, and finishing at the start line at a progressively increased speed 225 controlled by audio bleeps on a tape recorder. Between each shuttle, the subjects had 10-s 226 recovery time, consisting of $2 \times 5$-m of slowly jogging, but had to be stationary on the start line 227 ready for the next shuttle. The test protocol started with four running bouts at $10-13 \mathrm{~km} / \mathrm{h}$ and 228 another seven runs at $13.5-14 \mathrm{~km} / \mathrm{h}$, thereafter it continues with stepwise $0.5 \mathrm{~km} / \mathrm{h}$ speed 229 increments after every eight running bouts until exhaustion. When the subjects failed twice to 230 reach the finishing line in time, the distance covered was recorded and represents the test result.

\section{Statistical analyses}

233 Data are presented as group mean values and standard deviations (mean $\pm \mathrm{SD}$ ). After normal 234 distribution was examined using the Shapiro-Wilk-Test, an independent samples t-test was 235 calculated to determine significant differences between-group baseline values (W0).

236 All parameters were compared using 2 repeated measures analysis of variance (2-RM237 ANOVA), Group (SPI or PLA) $\times$ Time $(\mathrm{W} 0$ or W7), respectively. The significance level was 238 set at $p<0.05$. Relative reliability was assessed using the intraclass correlation coefficient (ICC) 239 between the test and retest ( 2 trials performed for vertical jump and sprint measures at W0) 240 [33]. An ICC < 0.40 was considered low; between 0.40 and 0.70 acceptable; between 0.70 and 2410.90 good and $>0.90$ excellent [34]. All analyses were performed using Statistical Package for 242 Social Sciences (SPSS) version 20. 


\section{Results}

246

247

248

249

250

251

252

253

254

255

256

257

258

259

260

261

262

263

264

265

266

267

268

269

\section{Compliance, diet, internal training load and test-retest reliability}

SPI and PLA supplementation compliance was $98.3 \%$ and $92.3 \%$, respectively. No adverse effects were reported during or after spirulina supplementation. Neither internal training load nor dietary intake showed differences between groups at W0 and W7 (Table 3).

$<<$ Please insert table 3 here $>>$

Table 4 illustrates the ICC of vertical jump and speed measures. Excellent relative reliability was observed for these measures.

$<<$ Please insert table 4 here $>>$

\section{Anthropometric data and body composition}

At W0, all anthropometric measurements and body composition did not differ between groups. For anthropometric data, a significant main effect of "Time" was observed only for FM $(p<0.01)$. The FM percentage was significantly reduced in both groups $(-5 \%, p<0.05)$. No significant main effect of "Group" or "Group $\times$ Time" interaction was observed for all anthropometric parameters. Thus, spirulina supplementation did not potentiate the loss of FM induced by training.

\section{Physical Fitness}

At W0, physical fitness measurements did not differ between groups.

Isokinetic Leg strength and power 
270 No significant main effect of "Time" or "Group" and no significant "Group $\times$ Time" interaction 271 were detected for the concentric and eccentric peak torque and power in knee extensors and 272 flexors meaning that, neither training alone (PLA) nor training associated with spirulina 273 supplementation affects leg maximal strength and power. Data are presented in Table 5.

274

275

276

277

278

279

280

281

282

283

284

285

286

287

288

289

290

291

292

293

294
$<<$ Please insert table 5 here $>>$

\section{Vertical jump}

A significant "Time" main effect was observed for SJ $(\mathrm{p}<0.01)$ and $\mathrm{CMJ}(\mathrm{F}=13.03, \mathrm{p}<0.01)$. Within-groups analysis showed significant improvements in SJ only for the SPI group $(\mathrm{p}<0.05)$ and for both groups in $\mathrm{CMJ}(\mathrm{p}<0.05)$ (Fig. 2A and 2B). Moreover, the percentage change in vertical jump parameters was always higher in SPI group compared to the PLA group (SJ: 3.4 vs $2.3 \%$; CMJ: 4.4 vs $3.6 \%$, respectively). Despite this, no significant "Group $\times$ Time" interaction or main effect of "Group" was observed for vertical jump measurements.

\section{Speed}

The statistical analysis indicated a significant main effect of "Time" for 10-m $(\mathrm{p}<0.05)$ and 30$\mathrm{m}(\mathrm{p}<0.05)$ sprint measurements. Within-groups analysis showed significant improvements in 10- and 30-m sprint time only for the SPI group ( $\mathrm{p}<0.05$ ) (Fig. 2C and 2D). Moreover, the percentage change in both sprint measurements was higher for SPI compared to the PLA group (10-m: -2.2 vs $-0.8 \%$; 30-m: -1.1 vs $-0.5 \%$, in SPI and PLA, respectively). However, no main significant effect of "Group" and "Group $\times$ Time" interaction was detected for speed measurements.

$<<$ Please insert Figure 2 here $>>$ 
296 Aerobic fitness

297 No significant main effect of "Time" or "Group" and no significant "Group $\times$ Time" interaction

298 was detected for the total distance covered in the yoyo IRT-1 meaning that neither training 299 alone (PLA) nor training associated with spirulina supplementation affect aerobic fitness 300 (1871.1-1993.3 vs 1940-1947.5 m at W0-W7 for SPI and PLA, respectively). 


\section{Discussion}

302

To our knowledge, this is the first study to examine the effects of Arthrospira platensis supplementation on anthropometric measurements as well as on physical performance using a battery of tests (leg strength, vertical jump, speed, and yoyo IRT-1 performances) in elite rugby players. Our hypothesis is partially verified since spirulina had no effect on anthropometric parameters and had only modest effects on performance (increase in vertical jump and sprint performance only for the SPI group without significant differences between groups).

Intense training has been shown to decrease the availability of essential amino acids, which may slow the rate of tissue repair and growth [35]. Athletes need to ingest enough high-quality protein in their diet to maintain essential amino acid availability during training and competition [36] and to generate a greater stimulus for muscle growth and enhanced recovery, potentially resulting in greater strength gains $[37,38]$. The supposed effects of spirulina on muscle development are based on its high protein content, especially in essential amino acids such as leucine, valine, isoleucine. For these reasons, athletes use spirulina to improve body composition (especially LBM) and physical performance.

Few studies have documented the effects of spirulina supplementation on anthropometric measurements and physical performance in athletes. To our knowledge, only one study [15] examined the effects of 2-weeks of spirulina platensis supplementation on anthropometric parameters and body composition in athletes and reported no significant effect. Our results confirm the latter, because even with a longer time supplementation (7-weeks), we did not report any additive effect of spirulina supplementation to the training program since rugby players had similar FM loss $(-5 \%)$ in both groups. The general consensus is that FM decreases with higher levels of play [39]. Moreover, the intensive training program of elite rugby players induces a significant decrease in FM, which makes it difficult to highlight the synergistic effect of spirulina. In pathological subjects, literature reported a decrease in BM and FM [40] after 
326 spirulina platensis supplementation. The underlying mechanism of the anti-obesity effects of

327 spirulina have been rarely discussed, but it seems that spirulina may be effective in lowering 328 BM and FM by reducing appetite [14]. These discrepancies between elite and pathological 329 subjects are not so paradoxical because it is more difficult to highlight anthropometric effects 330 of spirulina in elite athletes compared to obese or diabetic subjects who exhibit deleterious body 331 composition before supplementation.

Concerning spirulina effects on performance, due to its high protein content and nutritional quality compared to animal and vegetable proteins [41, 42], spirulina could be of interest to improve the LBM of athletes and consequently to increase strength, power and also field performances requiring elevated muscle mass such as vertical jump, sprint performance and distance covered during the Yo-Yo IRT-1. We showed no significant effects of spirulina on concentric and eccentric peak torques and power of the quadriceps and hamstring muscles.

Contrary to our results, Sandhu et al. [18] reported significant improvements in isometric peak force, average force, and fatigue index after eight weeks of spirulina supplementation $(2 \mathrm{~g} /$ day $)$ in trained and untrained subjects. These apparent contradictory results could be explained by differences in assessment method (isokinetic dynamometer vs the HUR1* 5340 Leg Extension/Curl), the type of contraction (concentric and eccentric vs isometric) and subject's training level (elite vs. university competitive level). No other study examined the effects of spirulina supplementation on muscular strength.

346 With regards to power proxies, Juszkiewicz et al. [19] recently showed that spirulina platensis 347 supplementation ( $1.5 \mathrm{~g} / \mathrm{d}$ for 6 weeks) was not able to enhance the mean power output during a 348 2000-m test on a rowing ergometer with a Polish rowing team. These findings are in accordance 349 with our results showing no effects of SPI on knee extensors and flexors isokinetic power. 
350 Concerning vertical jump and sprint performance, to our knowledge, no study has examined

351 the effects of spirulina supplementation. Our results did not demonstrate any significant

352 difference between groups but showed a significant increase in vertical jump performance with 353 greater percentage changes in the SPI group for SJ (3.4 vs $2.3 \%)$ and CMJ (4.4 vs $3.6 \%$ )

354 compared to PLA. Concerning sprint performance, only significant improvements were found 355 for both 10-m and 30-m sprint but within-groups effects were significant only in the SPI group.

356 Similarly, to vertical jump performance, better improvement magnitudes were found in the SPI 357 compared to PLA group for $10-\mathrm{m}(-2.7$ vs $-0.8 \%)$ and $30-\mathrm{m}$ sprint time $(-1.6$ vs $-0.5 \%)$. As 358 previously reported, it is more difficult to highlight the synergistic effects of spirulina on 359 performance in this elite population since physical qualities involved in sprint and vertical jump 360 were already reinforced in their training program.

361 Regarding aerobic performance, our results showed no significant effects of SPI ("Time" and 362 "Group" main effects or "Group $\times$ Time" interaction) on the total distance covered in the yoyo 363 IRT-1. Our hypothesis was not confirmed. This is not so surprising because spirulina had no 364 synergistic effect with training on BM and FM. In literature, spirulina supplementation effect 365 on aerobic fitness was documented by only a few studies. Lu et al. [16] reported in untrained 366 men a within-group increase in all-out treadmill time to exhaustion after 3-weeks of spirulina 367 platensis supplementation without significant "Group $\times$ Time" interaction. Similarly, Kalafati 368 et al. [17] also reported in moderately trained men a significant higher time to fatigue at $95 \%$ $369 \mathrm{VO}_{2 \max }$ after spirulina platensis supplementation. Perhaps, these conflicting findings may be 370 due to the intermittent character of the test and the different training status of our subjects (elite 371 vs. untrained and moderate trained).

372

373 To summarize, the effects of spirulina on body composition and performance using a battery of 374 tests are modest in elite rugby players. The limited beneficial effects only concern vertical jump 
375 and sprint performance. We cannot consider spirulina as a nutritional ergogenic aid in this

376 population. Our study does not confirm the assertions mentioned by the various commercial

377 sites, in particular, those specialized for elite athletes. With speculation, it is possible that the

378 results could be different with a longer duration ( $>7$ weeks) and a higher dose ( $>5.7 \mathrm{~g} /$ day).

379 Indeed, to our knowledge, no study has investigated the spirulina dose-response relationship in

380 athletes taking into account their training load. Since the optimal dose for such a population

381 with high training loads remains unclear, the dose used in this study might have influenced the

382 results. Further studies are required to verify spirulina consumption effects among athletes of

383 different sports, age, sex, and athletic level with longer durations and higher dosages taking into

384 account the relationship between the training load and the selected supplementation dose.

\section{Conclusion}

387 Seven weeks of spirulina supplementation in elite athletes did not improve body composition 388 nor substantially increase physical performance evaluated by a battery of tests (muscle strength, 389 power, speed, and aerobic fitness). We only observed a small advantage in vertical jump and 390 sprint performance in the SPI group. The assertions mentioned by commercial sales sites are 391 far from scientific reality. It is preferable to await further studies before recommending spirulina 392 supplementation to high-level athletes in order to improve body composition and physical 393 performance.

394

\section{Acknowledgments and funding statement}

396 This study (SUPERF study - FANTASIO project) was supported by the Brittany Region and 397 the competitiveness pole "Valorial, osons l'aliment plus intelligent". Spirulina was provided by 398 the society "Algae Green Value". There is no conflict of interests for the authors of this paper. 
399 We acknowledge the medical staff (Dr Pierrick Guillemot, Violaine Hamon, Dr Patrice 400 N'Gassa), the technical staff (Yann Moison, Yoann Carnot) and all the rugby players for their 401 involvement in the study.

402 The authors would like to thank the Professor David G. Behm for his perusal of our manuscript. 403

\section{Authors' contribution}

405 Chaouachi Mehdi: Data curation, Formal analysis, Investigation, Methodology, Software, 406 Validation, Roles/Writing - original draft - review \& editing, Validation;

407 Gautier Sandrine, Moison Yann, and Collin Tom: Data curation, Investigation;

408 Carnot Yoann: Data curation, Investigation, Software;

409 Bideau Nicolas: Data curation, Investigation, Software, Methodology;

410 Guillemot Pierrick: Data curation, Investigation, Methodology;

411 Groussard Carole, and Vincent Sophie: Conceptualization; Formal analysis, Funding 412 acquisition, Investigation, Methodology, Project administration, Supervision, Writing - review 413 \& editing, Validation;

414 All authors have read and approved the final version of the manuscript, and agree with the order 415 of presentation of the authors.

\section{Conflict of interest}

417 The authors declare no conflict of interests with the information contained within this 418 manuscript. 
1. Deng, R. and T.J. Chow, Hypolipidemic, antioxidant, and antiinflammatory activities of microalgae Spirulina. Cardiovasc Ther, 2010. 28(4): p. e33-45.

2. Koncic, M.Z. and M. Tomczyk, New insights into dietary supplements used in sport: active substances, pharmacological and side effects. Curr Drug Targets, 2013. 14(9): p. 1079-92.

3. Vicat, J.-P., J.-C.D. Mbaigane, and Y. Bellion, Teneurs en éléments majeurs et traces de spirulines (Arthrospira platensis) originaires de France, du Tchad, du Togo, $d u$ Niger, du Mali, du Burkina-Faso et de République centrafricaine. Comptes Rendus Biologies, 2014. 337(1): p. 44-52.

4. Serban, M.C., et al., A systematic review and meta-analysis of the impact of Spirulina supplementation on plasma lipid concentrations. Clin Nutr, 2015. 35(4): p. 842-851.

5. Thengodkar, R.R. and S. Sivakami, Degradation of Chlorpyrifos by an alkaline phosphatase from the cyanobacterium Spirulina platensis. Biodegradation, 2010. 21(4): p. 637-44.

6. Khan, Z., P. Bhadouria, and P.S. Bisen, Nutritional and therapeutic potential of Spirulina. Curr Pharm Biotechnol, 2005. 6(5): p. 373-9.

7. Sotiroudis, T.G. and G. Sotiroudis, Health aspects of Spirulina (Arthrospira) microalga food supplement. Journal of the Serbian Chemical Society, 2013. 78(3): p. 395-405.

8. Marzieh Hosseini, S., et al., Spirulina paltensis: Food and function. Current Nutrition \& Food Science, 2013. 9(3): p. 189-193.

9. Kulshreshtha, A., et al., Spirulina in health care management. Curr Pharm Biotechnol, 2008. 9(5): p. 400-5.

10. Wu, Q., et al., The antioxidant, immunomodulatory, and anti-inflammatory activities of Spirulina: an overview. Arch Toxicol, 2016. 90(8): p. 1817-40.

11. Miczke, A., et al., Effects of spirulina consumption on body weight, blood pressure, and endothelial function in overweight hypertensive Caucasians: a double-blind, placebocontrolled, randomized trial. Eur Rev Med Pharmacol Sci, 2016. 20(1): p. 150-6.

12. Zeinalian, R., et al., The effects of Spirulina Platensis on anthropometric indices, appetite, lipid profile and serum vascular endothelial growth factor (VEGF) in obese individuals: a randomized double blinded placebo controlled trial. BMC Complement Altern Med, 2017. 17(1): p. 225.

13. Lee, E.H., et al., A randomized study to establish the effects of spirulina in type 2 diabetes mellitus patients. Nutr Res Pract, 2008. 2(4): p. 295-300.

14. Mazokopakis, E.E., et al., The hypolipidaemic effects of Spirulina (Arthrospira platensis) supplementation in a Cretan population: a prospective study. J Sci Food Agric, 2014. 94(3): p. 432-7.

15. Milasius, K., R. Malickaite, and R. Dadeliene, Effect of Spirulina food supplement on blood morphological parameters, biochemical composition and on the immune function of sportsmen. Biology of Sport, 2009. 26(2): p. 157-172.

16. Lu, H.K., et al., Preventive effects of Spirulina platensis on skeletal muscle damage under exercise-induced oxidative stress. Eur J Appl Physiol, 2006. 98(2): p. 220-6.

17. Kalafati, M., et al., Ergogenic and antioxidant effects of spirulina supplementation in humans. Med Sci Sports Exerc, 2010. 42(1): p. 142-51.

18. Sandhu, J., B. Dheera, and S. Shweta, Efficacy of Spirulina Supplementation on Isometric Strength and Isometric Endurance of Quadriceps in Trained and Untrained Individuals--a comparative study. Ibnosina Journal of Medicine \& Biomedical Sciences, 2010. 2(2): p. 79-86. 
468

469

470

471

472

473

474

475

476

477

478

479

480

481

482

483

484

485

486

487

488

489

490

491

492

493

494

495

496

497

498

499

500

501

502

503

504

505

506

507

508

509

510

511

512

513

514

515

516

517

19. Juszkiewicz, A., et al., An attempt to induce an immunomodulatory effect in rowers with spirulina extract. J Int Soc Sports Nutr, 2018. 15: p. 9.

20. Schröder, H., et al., The type, amount, frequency and timing of dietary supplement use by elite players in the First Spanish Basketball League. J Sports Sci, 2002. 20(4): p. 353-8.

21. Sekulic, D., et al., Substance use and misuse and potential doping behaviour in rugby union players. Res Sports Med, 2014. 22(3): p. 226-39.

22. Fox, R.D., Spirulina: Production \& Potential. 1996, Aix-en-Provence: Edisud.

23. Bovenschen, H.J., et al., Evaluation of a gastrointestinal symptoms questionnaire. Dig Dis Sci, 2006. 51(9): p. 1509-15.

24. Siri, W.E., The gross composition of the body. Adv Biol Med Phys, 1956. 4: p. 239-80.

25. Comyns, T. and E.P. Flanagan, Applications of the session rating of perceived exertion system in professional rugby union. Strength Cond J, 2013. 35(6): p. 78-85.

26. Haddad, M., et al., Validity and psychometric evaluation of the French version of RPE scale in young fit males when monitoring training loads. Science \& Sports, 2013. 28(2): p. e29-e35.

27. Maffiuletti, N.A., et al., Reliability of knee extension and flexion measurements using the Con-Trex isokinetic dynamometer. Clin Physiol Funct Imaging, 2007. 27(6): p. 34653.

28. Lehance, C., J.-L. Croisier, and T. Bury, Optojump system efficiency in the assessment of lower limbs explosive strength. Science \& Sports, 2005. 20(3): p. 131-135.

29. Glatthorn, J.F., et al., Validity and reliability of Optojump photoelectric cells for estimating vertical jump height. J Strength Cond Res, 2011. 25(2): p. 556-60.

30. Chaouachi, M., et al., Within Session Sequence of Balance and Plyometric Exercises Does Not Affect Training Adaptations with Youth Soccer Athletes. J Sports Sci Med, 2017. 16(1): p. 125-136.

31. Krustrup, P., et al., The yo-yo intermittent recovery test: physiological response, reliability, and validity. Med Sci Sports Exerc, 2003. 35(4): p. 697-705.

32. Bangsbo, J., F.M. Iaia, and P. Krustrup, The Yo-Yo intermittent recovery test : a useful tool for evaluation of physical performance in intermittent sports. Sports Med, 2008. 38(1): p. 37-51.

33. Shrout, P.E. and J.L. Fleiss, Intraclass correlations: uses in assessing rater reliability. Psychol Bull, 1979. 86(2): p. 420-8.

34. Hopkins, W.G., et al., Progressive statistics for studies in sports medicine and exercise science. Med Sci Sports Exerc, 2009. 41(1): p. 3-13.

35. Kreider, R.B., Dietary supplements and the promotion of muscle growth with resistance exercise. Sports Med, 1999. 27(2): p. 97-110.

36. Kerksick, C.M., et al., The effects of protein and amino acid supplementation on performance and training adaptations during ten weeks of resistance training. $\mathrm{J}$ Strength Cond Res, 2006. 20(3): p. 643-53.

37. Kraemer, W.J. and B.A. Spiering, Skeletal muscle physiology: plasticity and responses to exercise. J Hormone Research in Paediatrics, 2006. 66(Suppl. 1): p. 2-16.

38. Ratamess, N.A., et al., The effects of amino acid supplementation on muscular performance during resistance training overreaching. J Strength Cond Res, 2003. 17(2): p. 250-8.

39. Duthie, G., D. Pyne, and S. Hooper, Applied physiology and game analysis of rugby union. Sports Med, 2003. 33(13): p. 973-91.

40. Moradi, S., et al., Effects of Spirulina supplementation on obesity: A systematic review and meta-analysis of randomized clinical trials. Complement Ther Med, 2019. 47: p. 102211. 
518 41. Becker, E.W., Micro-algae as a source of protein. Biotechnol Adv, 2007. 25(2): p. 207$519 \quad 10$.

520 42. Lupatini, A.L., et al., Potential application of microalga Spirulina platensis as a protein $521 \quad$ source. J Sci Food Agric, 2017. 97(3): p. 724-732. 
Table 1. Participant anthropometric characteristics.

\begin{tabular}{|lcc|}
\hline & SPI $(\mathbf{n}=\mathbf{1 1})$ & PLA $(\mathbf{n}=\mathbf{1 1})$ \\
\hline Age (year) & $25.8 \pm 3.4$ & $26.3 \pm 4.4$ \\
\hline BM (kg) & $100.0 \pm 13.6$ & $99.1 \pm 19.9$ \\
\hline Height (cm) & $184.1 \pm 7.7$ & $182.4 \pm 7.7$ \\
\hline FM (\%) & $19.7 \pm 4.6$ & $19.3 \pm 4.8$ \\
\hline FM (kg) & $20.2 \pm 6.5$ & $19.8 \pm 8.0$ \\
\hline LBM (kg) & $79.8 \pm 8.0$ & $79.4 \pm 12.7$ \\
\hline
\end{tabular}

Values are presented as mean \pm standard deviation. BM, body mass; FM, Fat Mass; LBM, lean body mass. 
Table 2. Composition of Arthrospira platensis produced by AGV (100 g).

\begin{tabular}{|c|c|c|c|c|c|}
\hline & Unity & Amount & & Unity & Amount \\
\hline \multirow[t]{3}{*}{ Energy } & & & Vitamins & & \\
\hline & $\mathrm{kJ}$ & 1530 & Vitamin A & $\mu g$ & $<20$ \\
\hline & kcal & 363 & $\beta$-carotene & $\mathrm{mg}$ & 24,902 \\
\hline \multicolumn{3}{|l|}{ Fat } & Vitamin C & $\mathrm{mg}$ & $<2,5$ \\
\hline Total fat & $\mathrm{g}$ & 6,3 & Vitamin B3 & $\mathrm{mg}$ & 8,5 \\
\hline Saturated fat & g & 3,8 & Vitamin B5 & $\mathrm{mg}$ & 0,05 \\
\hline Unsaturated fat & $\mathrm{g}$ & 2,5 & Vitamin B6 & $\mathrm{mg}$ & 0,09 \\
\hline Monounsaturated fat & $\mathrm{g}$ & 0,4 & Vitamin B9 & $\mu g$ & 156 \\
\hline Polyunsaturated fat & $\mathrm{g}$ & 2 & Vitamin B12 & $\mu \mathrm{g}$ & 61,3 \\
\hline Omega 3 & $\%$ & 0,12 & Vitamin E & $\mathrm{mg}$ & 6,84 \\
\hline Omega 6 & $\%$ & 14,31 & \multicolumn{2}{|l|}{ Minerals } & \\
\hline Carbohydrates & & & Sodium & $\mathrm{mg}$ & 1338,2 \\
\hline Total Carbohydrates & 2 & 16,5 & Phosphorus & $\mathrm{mg}$ & 1353,8 \\
\hline Dietary Fiber & g & 7,4 & Calcium & $\mathrm{mg}$ & 310,4 \\
\hline \multicolumn{3}{|c|}{ Proteins and amino acids } & Copper & $\mathrm{mg}$ & 1,83 \\
\hline Proteins & $\mathrm{g}$ & 63,7 & Iron & $\mathrm{mg}$ & 76,43 \\
\hline Leucine & $\mathrm{g}$ & 5,56 & Magnesium & $\mathrm{mg}$ & 434,2 \\
\hline Isoleucine & $\mathrm{g}$ & 3,47 & Manganese & $\mathrm{mg}$ & 7,06 \\
\hline \multirow[t]{2}{*}{ Valine } & $\mathrm{g}$ & 4,02 & Potassium & $\mathrm{mg}$ & 1932 \\
\hline & & & Zinc & $\mathrm{mg}$ & 7,43 \\
\hline
\end{tabular}


Table 3. Participant's dietary intake and internal training load.

\begin{tabular}{|lcccc|}
\hline & & SPI (n=11) & PLA (n=11) & $p$-value \\
\hline \multirow{2}{*}{ Caloric intake (kcal) } & W0 & $2680.8 \pm 495.4$ & $2844.8 \pm 495.4$ & 0.508 \\
\cline { 2 - 5 } & W7 & $2788.3 \pm 535.6$ & $2646.8 \pm 523.6$ & 0.558 \\
\hline \multirow{2}{*}{ Carbohydrates (g) } & W0 & $2.83 \pm 0.91$ & $2.85 \pm 0.96$ & 0.948 \\
\cline { 2 - 5 } & W7 & $3.05 \pm 0.99$ & $2.64 \pm 0.89$ & 0.350 \\
\hline \multirow{3}{*}{ Proteins (g) } & W0 & $1.37 \pm 0.38$ & $1.66 \pm 0.66$ & 0.243 \\
\cline { 2 - 5 } Fat (g) & W7 & $1.43 \pm 0.36$ & $1.62 \pm 0.64$ & 0.416 \\
\hline \multirow{3}{*}{ Internal training load } & W0 & $1.15 \pm 0.32$ & $1.09 \pm 0.37$ & 0.718 \\
\cline { 2 - 5 } (AU) & W7 & $1.16 \pm 0.33$ & $1.10 \pm 0.45$ & 0.735 \\
\cline { 2 - 5 } & W1 & $1408.1 \pm 434.2$ & $1258.9 \pm 579.4$ & 0.531 \\
\cline { 2 - 5 } & W2 & $1317.4 \pm 358.9$ & $1218.2 \pm 695.2$ & 0.696 \\
\cline { 2 - 5 } & W4 & $1192.0 \pm 244.9$ & $1206.5 \pm 424.9$ & 0.927 \\
\cline { 2 - 5 } & W5 & $1296.4 \pm 399.2$ & $1562.6 \pm 631.0$ & 0.268 \\
\cline { 2 - 5 } & W6 & $1592.6 \pm 316.0$ & $1740.8 \pm 414.8$ & 0.372 \\
\hline
\end{tabular}

Values are presented as mean \pm standard deviation. 
Table 4: ICC of vertical jump and speed measurements

\begin{tabular}{|lcc|}
\hline Measures & ICC & Interpretation \\
\hline SJ & 0.958 & Excellent \\
\hline CMJ & 0.980 & Excellent \\
\hline 10-m Sprint & 0.900 & Excellent \\
\hline 30-m Sprint & 0.937 & Excellent \\
\hline
\end{tabular}

ICC, intraclass correlation coefficient; SJ, squat jump; CMJ, countermovement jump. 
Table 5. Isokinetic leg strength and power before and after supplementation

\begin{tabular}{|c|c|c|c|c|c|}
\hline & & \multicolumn{2}{|c|}{ Peak torque (Nm) } & \multicolumn{2}{|c|}{ Maximal power $(W)$} \\
\hline & & W0 & W7 & W0 & W7 \\
\hline \multirow{2}{*}{ CON $60 \mathrm{E}$} & PLA & $\begin{array}{c}263.20 \pm \\
22.72 \\
\end{array}$ & $\begin{array}{c}273.82 \pm \\
27.68 \\
\end{array}$ & $\begin{array}{c}275.61 \pm \\
23.80 \\
\end{array}$ & $\begin{array}{c}286.75 \pm \\
28.99 \\
\end{array}$ \\
\hline & SPI & $\begin{array}{c}278.42 \pm \\
15.64 \\
\end{array}$ & $\begin{array}{c}271.96 \pm \\
26.97 \\
\end{array}$ & $\begin{array}{c}291.57 \pm \\
16.37 \\
\end{array}$ & $\begin{array}{c}284.79 \pm \\
28.24 \\
\end{array}$ \\
\hline \multirow{2}{*}{ CON $60 \mathrm{~F}$} & PLA & $\begin{array}{c}183.59 \pm \\
30.18 \\
\end{array}$ & $\begin{array}{c}192.37 \pm \\
43.81 \\
\end{array}$ & $\begin{array}{c}192.27 \pm \\
31.60 \\
\end{array}$ & $\begin{array}{c}201.46 \pm \\
45.88 \\
\end{array}$ \\
\hline & SPI & $\begin{array}{c}190.32 \pm \\
30.81 \\
\end{array}$ & $\begin{array}{c}184.55 \pm \\
30.29 \\
\end{array}$ & $\begin{array}{c}199.31 \pm \\
32.26\end{array}$ & $\begin{array}{c}193.25 \pm \\
31.71\end{array}$ \\
\hline \multirow{2}{*}{ CON 240 E } & PLA & $\begin{array}{c}213.55 \pm \\
24.41\end{array}$ & $\begin{array}{c}213.21 \pm \\
31.77\end{array}$ & $\begin{array}{c}947.28 \pm \\
162.39\end{array}$ & $\begin{array}{c}906.83 \pm \\
103.02\end{array}$ \\
\hline & SPI & $\begin{array}{c}226.15 \pm \\
38.76\end{array}$ & $\begin{array}{c}216.49 \pm \\
24.59\end{array}$ & $\begin{array}{c}849.51 \pm \\
102.25\end{array}$ & $\begin{array}{c}893.08 \pm \\
133.07\end{array}$ \\
\hline \multirow{2}{*}{ CON 240 F } & PLA & $\begin{array}{c}170.03 \pm \\
34.97\end{array}$ & $\begin{array}{c}179.25 \pm \\
43.45 \\
\end{array}$ & $\begin{array}{c}727.23 \pm \\
141.31 \\
\end{array}$ & $\begin{array}{c}724.69 \pm \\
166.01 \\
\end{array}$ \\
\hline & SPI & $\begin{array}{c}173.61 \pm \\
33.73 \\
\end{array}$ & $\begin{array}{c}173.01 \pm \\
39.63 \\
\end{array}$ & $\begin{array}{c}712.22 \pm \\
146.46 \\
\end{array}$ & $\begin{array}{c}750.83 \pm \\
181.99 \\
\end{array}$ \\
\hline \multirow{2}{*}{ ECC 30 E } & PLA & $\begin{array}{c}287.28 \pm \\
38.64\end{array}$ & $\begin{array}{c}308.75 \pm \\
29.95 \\
\end{array}$ & $\begin{array}{c}111.82 \pm \\
12.77 \\
\end{array}$ & $\begin{array}{c}111.64 \pm \\
16.63 \\
\end{array}$ \\
\hline & SPI & $\begin{array}{c}316.67 \pm \\
16.53 \\
\end{array}$ & $\begin{array}{c}319.83 \pm \\
23.07 \\
\end{array}$ & $\begin{array}{c}118.40 \pm \\
20.28 \\
\end{array}$ & $\begin{array}{c}113.36 \pm \\
12.89 \\
\end{array}$ \\
\hline \multirow{2}{*}{ ECC $30 \mathrm{~F}$} & PLA & $\begin{array}{c}200.25 \pm \\
37.18\end{array}$ & $\begin{array}{c}186.38 \pm \\
42.51\end{array}$ & $\begin{array}{c}89.02 \pm \\
18.31\end{array}$ & $\begin{array}{c}93.85 \pm \\
22.76\end{array}$ \\
\hline & SPI & $\begin{array}{c}195.58 \pm \\
19.27\end{array}$ & $\begin{array}{c}196.55 \pm \\
25.39\end{array}$ & $\begin{array}{c}90.90 \pm \\
17.66\end{array}$ & $\begin{array}{c}90.58 \pm \\
20.75\end{array}$ \\
\hline
\end{tabular}

Nm, Newton metre; W, Watt ; CON, Concentric; ECC, Eccentric; E, extensors; F, Flexors; 60, 60\%; $240,240^{\circ} ; 30,30^{\circ}$. 

- Clinical examination and medical interrogatory.

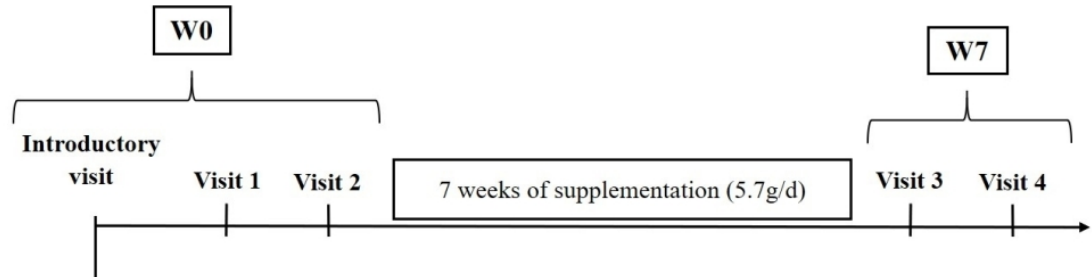

Visit 1 and 3

- Anthropometric measurements.

- Leg strength and power.

- 3-day dietary record.

Visit 2 and 4

- Vertical jump.

- Speed.

- yo-yo IRT 1.

Figure 1. Study design

$64 \times 31 \mathrm{~mm}(600 \times 600 \mathrm{DPI})$ 

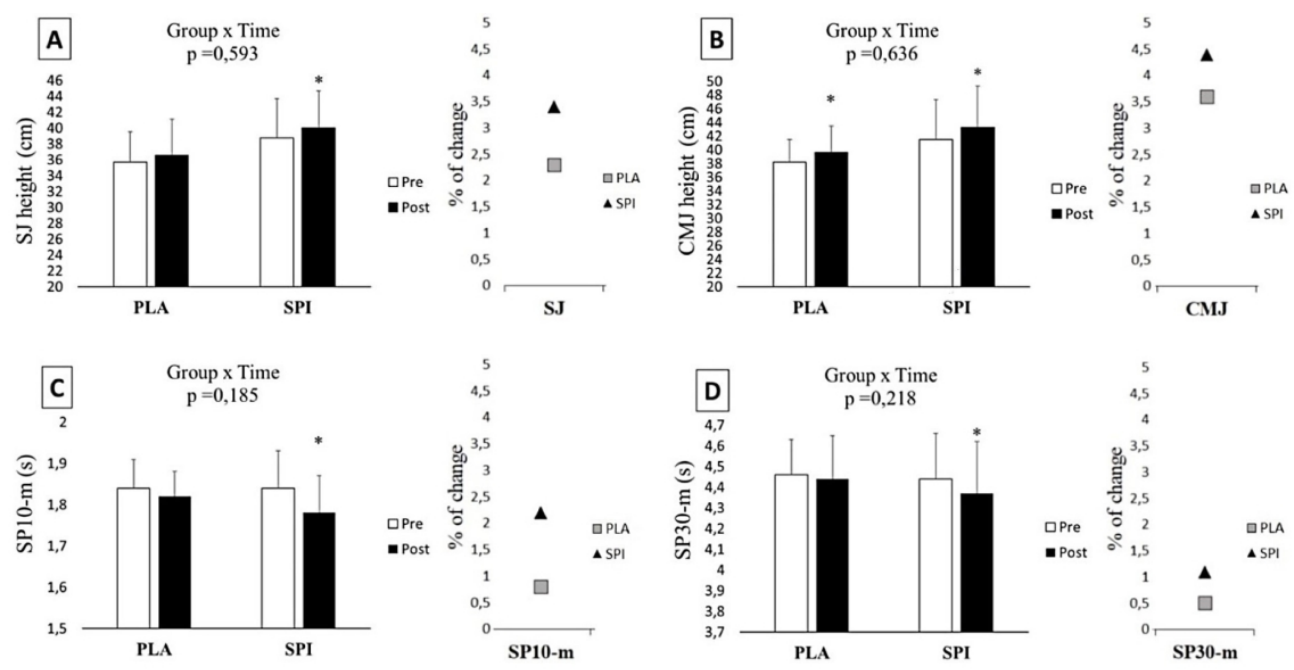

Figure 2. Effects of supplementation on Vertical jump and Speed measurements. ${ }^{*} p<0.05$

Figure 2. Effects of supplementation on Vertical jump and Speed measurements. ${ }^{*} p<0.05$ $97 \times 57 \mathrm{~mm}(600 \times 600 \mathrm{DPI})$ 